\title{
High Burden to High Impact (HBHI) Approaches - Country Perspective for Adoption and Adaptation in India
}

\author{
Roop Kumari', Himanshu Jayswar ${ }^{2}$, Neeraj Dhingra ${ }^{3}$ \\ ${ }^{1}$ Technical Officer, World Health Organization Country Office for India, New Delhi, India. \\ ${ }^{2}$ State Program Officer, Vector Borne Disease Control program, Directorate of Health Services, Bhopal, Madya Pradesh, India. \\ ${ }^{3}$ Director, National Vector Borne Diseases Control Program, Delhi, India.
}

DOI: https://doi.org/10.24321/0019.5138.202023

\section{I $\quad \mathbf{N} \quad \mathbf{F} \quad \mathbf{O}$}

\section{Corresponding Author:}

Roop Kumari, World Health Organization Country

Office, India.

E-mail Id:

kumarir@who.int

Orcid Id:

https://orcid.org/0000-0002-7850-5338

How to cite this article:

Kumari R, Jayswar H, Dhingra N. High Burden to High Impact (HBHI) Approaches - Country Perspective for Adoption and Adaptation in India. J Commun Dis 2020; 52(3): 5-16.

Date of Submission: 2020-04-01

Date of Acceptance: 2020-08-14

\section{$\begin{array}{llllllll}\mathbf{A} & \mathbf{B} & \mathbf{S} & \mathbf{T} & \mathbf{R} & \mathbf{A} & \mathbf{C} & \mathbf{T}\end{array}$}

In India, a National Framework for Malaria Elimination (NFME) has been developed and launched on 11 February 2016 align with the Global Technical Strategy (GTS) for malaria elimination 2016-2030. Malaria elimination will be carried out in a phased manner. In accordance with the NFME, National Strategy Plan for malaria elimination 2017-2022 has been developed by National Vector Borne Disease (NVBDCP), MoH \& FW, Govt. of India in collaboration with WHO Country Office India and launched in July 2017. The country has made significant improvement in the malaria situation in recent years. Reported malaria cases were reduced by $49 \%$ and deaths by $50 \%$ in 2018 compared to 2017 . However, India and ten countries in Africa contribute approximately $70 \%$ of the world's malaria cases and deaths. These countries adopted the "High Burden to High Impact (HBHI) approach". HBHI has four response elements: (i) Political will to reduce malaria deaths; (ii) Strategic information to drive impact, (iii) Better guidance, policies and strategies, and (iv) A coordinated national malaria response. India has adopted this approach in May 2019 to further accelerate and sustain the progress in the states with high malaria burden. Initially, $\mathrm{HBHI}$ approaches are being adopted by NVBDCP with the support of WHO in four high burden states namely Jharkhand, Chhattisgarh, West Bengal and Madhya Pradesh. During the first phase, an in-depth situation analysis on malaria in these states have been conducted using the tools provided by WHO. Key features of adaptation of $\mathrm{HBHI}$ approaches in India and detail analysis of one state Madhya Pradesh are presented in the article.

Keywords: Malaria, India, Epidemiology, stratification, $\mathrm{HBHI}$, High burden, Plasmodium falciparum, Plasmodium Vivax, Madhya Pradesh

\section{Introduction}

Malaria is caused by parasites of the Plasmodium family and transmitted by female Anopheles mosquitoes. Despite being preventable and treatable, malaria continues to have a devastating impact on people's health and livelihoods around the world. However, malaria is both preventable 
and curable and increased efforts have yielded positive results, reducing the malaria burden in several countries. The World Health Organization (WHO) has developed the Global Technical Strategy (GTS) for malaria Elimination 2016-2030 ${ }^{1}$. The strategy sets the targets of reducing global malaria incidence and mortality rates by at least $40 \%$ by 2020, at least $75 \%$ by 2025 and at least $90 \%$ by 2030 .

While tremendous strides have been made over recent years in reducing the number of cases and deaths from malaria, the estimates in the World Malaria Report ${ }^{2}$ demonstrate that progress has stalled in high burden countries. Approximately $70 \%$ of the world's malaria burden is concentrated in just 11 countries - 10 in sub-Saharan Africa and India.

According to the World Malaria Report $2018^{2}$, there were 219 million cases of the disease in 2017, compared to 217 million the year before the report's finding that, among the ten highest burden African countries, there were 3.5 million more cases in 2017 over the previous year is cause for concern. So, in 2017, all the ten highest burden African countries reported increases in malaria cases over the previous year. Only India marked progress in reducing its disease burden (WMR, 2018) ${ }^{2}$.Global progress in reducing deaths has also slowed. Estimated deaths due to malaria fell globally from 585,000 in 2010 to 405,000 in 2018 as per WMR. However, the rate of reduction of malaria mortality was slower in the period 2016-2018 than in the period 2010-2015 (WMR 2019). . There was a great concern and the need for an immediate change in approach against a disease that is both preventable and curable.

\section{High Burden High Impact Approaches}

To get back on track, stepped-up action is needed across all endemic countries, particularly in countries hardest hit by malaria. In May 2018, at the 71st World Health Assembly, the WHO called for an aggressive new approach to accelerate progress against malaria. Heeding the call, ministries of health in affected nations have been working with WHO and the RBM partnership to end malaria to map out a way forward - the "High Burden High Impact (HBHI): a targeted malaria response". ${ }^{4}$ The new response has been prioritized by several partners; and the WHO DirectorGeneral has made it a flagship initiative of the Organization. Ten countries in Africa (Burkina Faso, Cameroon, Democratic Republic of the Congo, Ghana, Mali, Mozambique, Niger, Nigeria, Uganda and the United Republic of Tanzania) with the highest burden of malaria and India are the early adopters of $\mathrm{HBHI}$ approach.

The HBHI approach was launched in November 2018 by WHO and the Roll Back malaria Partnership to End malaria, as a country driven response to achieve rapid and sustainable malaria impact. ${ }^{4}$ The country-led $\mathrm{HBHI}$ approach provides a response that can help to ensure future success in malaria control. Appropriate mixes of interventions will be scaled up using accessible and affordable frontline services. It is a mechanism to accelerate progress in countries that carry the highest burden of the disease. $\mathrm{HBHI}$ approaches demand high level political leadership, country ownership and commitment from a broad coalition of stakeholders. Actions focus on translating political commitment into tangible actions, better use of strategic information to drive impact, implementation of the best global guidance, policies and strategies as well as improved coordination.

\section{Key Elements of $\mathrm{HBHI}$}

Key elements of the new "HBHI" response include:

Political will to reduce malaria deaths: The approach calls on high burden countries and global partners to translate their stated political commitment into resources and tangible actions that will save more lives. Ownership of the challenge lies in the hands of governments most affected by malaria. Grassroots initiatives that empower people to take action to protect themselves from malaria, like the "Zero malaria Starts with Me" campaign ${ }^{5}$, can help foster an environment of accountability and action.

Strategic information to drive impact: We are moving away from a 'one-size-fits-all' approach to malaria. Through better analysis and the strategic use of quality data, countries can pinpoint where to deploy the most effective malaria control tools for maximum impact. They can also use data to optimize the way tools are delivered to those in need through all conduits of delivery, including improved primary health care. The use of strategic information to pinpoint where to deploy the most effective malaria control tools for maximum impact.

Better guidance, policies and strategies: WHO will draw on the best evidence to establish global guidance that can be adapted by high burden countries for a range of local settings. This guidance will be continually updated and refined based on country experience and the development of new tools.

A coordinated national malaria response: A key success factor is a more coordinated health sector response complemented by other sectors, such as environment, education and agriculture. Aligning partners behind this country-led approach will four ensure that scarce resources are used as efficiently as possible. We need better data, closer coordination among partners on the ground, and new and improved tools that will help us counter emerging resistance and other threats".

$\mathrm{HBHI}$ is a holistic approach, with the four elements feeding into tangible actions through NSP implementation and concrete outcomes. 


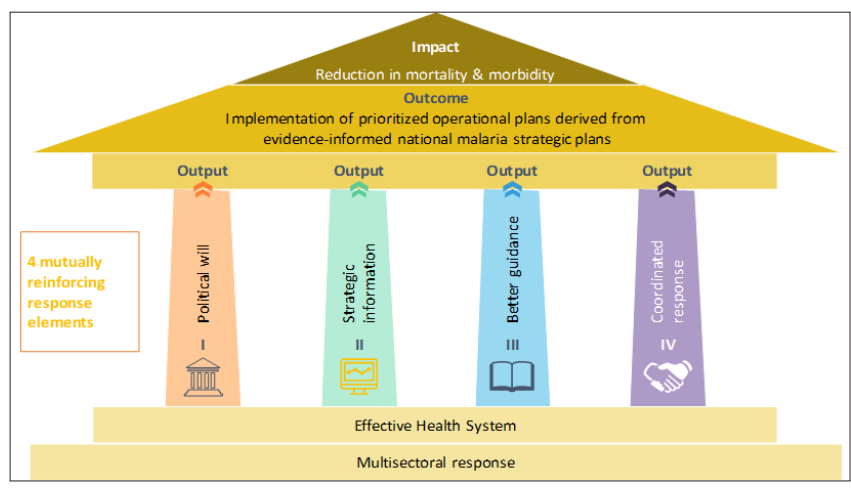

Figure I.Key elements of the "HBHI" response

\section{"HBHI" is guided by the following principles ${ }^{4}$}

- HBHI should be country-owned, country-led, and aligned with the GTS, the health-related Sustainable Development Goals (SDGs), national health goals, strategies and priorities;

- Focused on high burden settings;

- Able to demonstrate impact, with an intensified approach to reducing mortality while ensuring progress is on track to reach the GTS targets for reducing malaria cases;

- Characterized by packages of malaria interventions, optimally delivered through appropriate channels, including a strong foundation of primary health care.

\section{Malaria Database Development}

Countries that have launched the HBHI approach have already started developing national malaria database repositories to draw on health systems and other survey, research data and climate data to help understand the geographic distribution of the disease and the impact of interventions. ${ }^{6}$ Strengthening the use of available data for decision making will help identify the best mix of interventions and drives continuous improvement of quality data.

In India, there is a need to develop a similar data repository or national malaria databases at the NVBDCP. The database would aim to improve the quality of information available and, consequently, help identify the most effective policies and intervention tools to control and reduce the burden of the disease. We need better data, closer coordination among partners on the ground, and new and improved tools that will help us to fight against malaria.

\section{"Zero malaria starts with me" campaign}

Other key response highlights from 2019 include the launch or strengthening of social mobilization and advocacy movements through the "Zero malaria starts with me" campaign". ${ }^{.}$This is a grassroots campaign that aims to empower individuals and communities to protect themselves from malaria. On World Malaria Day 2020, WHO joins the RBM Partnership to End Malaria ${ }^{7}$ in promoting "Zero malaria starts with me". In line with WHO's push for universal health coverage and primary health care, $\mathrm{HBHI}$ will play an important role in ensuring that people who are most in need get access to the right interventions, including insecticide treated nets and medicines. The Global Fund to Fight AIDS, Tuberculosis and malaria also encourages national malaria programmes to adopt the $\mathrm{HBHI}$ approach when requesting funding and use local data to identify the mix of interventions and optimal means of delivery. The "Zero malaria starts with me" campaign engages all members of society: political leaders who control government policy decisions and budgets; private sector companies that will benefit from a malaria-free workforce; and communities affected by malaria, whose buy-in and ownership of malaria control interventions is key to success.

\section{Global Status of HBHI Approaches}

Sub-Saharan African leaders in the highest burden countries are moving quickly to adopt the " $\mathrm{HBHI}$ approach to jumpstart progress against malaria. Political will and commitment are being revitalized. Actions focus on translating political commitment into tangible actions, better use of strategic information to drive impact, implementation of the best global guidance, policies and strategies as well as improved coordination. $^{8}$

Stratification to identify and prioritize the right mix of interventions has been done except in Mali (scheduled in April 2020). Malaria program review has also been done in most of the HBHI countries and most of them are also updating their National Strategic Plans. Nigeria has secured funding from World Bank to adopt HBHI. High level meetings are being planned in many countries in 2020 with Health Ministers and key partners.

\section{India Status of HBHI Approaches}

\section{Overview of the Malaria Programme in India}

Malaria is one of the diseases under umbrella programme of NVBDCP, Ministry of Health \& Family Welfare, Government of India. The Directorate of NVBDCP is also responsible for the prevention and control of five other vector borne diseases namely, dengue, chikungunya, Japanese encephalitis, visceral leishmaniasis and lymphatic filariasis. This programme is an integral part of India's National Health Mission (NHM). The Government of India also has 19 Regional Offices for Health and Family Welfare (ROHFW), located in 19 states. One or more states are covered under the jurisdiction of each ROHFW. They perform a vital role in monitoring of NVBDCP activities in the states. Every state has a vector borne disease control unit under its Department of Health and Family Welfare, headed by the state Programme Officer. Each state has a state Health Society at the state level and District Health Societies 
through which funds are disbursed. They play a role in planning and monitoring of programme activities within the districts. At the district level, the vector borne disease control programme including malaria is managed by the District Malaria Officer (DMO) or District Vector Borne Disease Control Officer (DVBDCO).

\section{Malaria Situation in India}

Malaria is a major public health problem in India and one which contributes the highest malaria burden to the overall burden in Southeast Asia (WMR 2018). Historically, the highest incidence of malaria in India occurred in the 1950s, with an estimated 75 million cases and 0.8 million deaths per year. The launch of the National Malaria Control Program (NMCP) in 1953 resulted in a significant decline in the number of reported cases to $<50,000$ and no reported deaths, by 1961 . Despite its near elimination in the mid1960's, malaria resurged to 6.45 million cases in 1976. ${ }^{11}$ Since then, confirmed cases have gradually decreased.

Over the past 15 years, India has made considerable progress in reducing malaria burden in India, the case load, though steady around 2 million cases annually in the late nineties, has shown a declining trend since 2002. The Slide Positive Rate (SPR) has also shown gradual decline from 3.32 in 1995 to 0.26 in 2019 (NVBDCP data). Trends of malaria cases, deaths and Plasmodium falciparum \& Plasmodium vivax cases from year 2000 to 2019 are graphically depicted in Figure 2 which shows a significant decline of cases as well as deaths in the country.

In 2018, the reported malaria cases nationwide declined by $49.09 \%$ (429928 cases) compared to 2017 (844,558 cases) and the malaria deaths were reduced by $50.52 \%$ (from 194 in 2017 to 96) in 2018. As compared to previous year, reported malaria cases (provisional reported data) declined by 21.2\% from 429928 in 2018 to 338513 in 2019. The number of reported malaria deaths reduced from 96 to $73(24 \%)$ in the country. In total, $P$. vivax proportion in the country during 2019 was $53.64 \%$ while P falciparum was $46.36 \%$.
NVBDCP data shows that the map of malaria burden is shrinking in the country and more and more districts are shifting towards the lower API group. High burden areas have been significantly reduced. While this progress is highly commendable, the disease is still a major public health problem in many districts in several states.

India has made considerable progress in reducing malaria burden and has a vision of malaria free country by 2027 and elimination by 2030 . World Malaria Report has also documented the remarkable decline in malaria cases and deaths in India (WMR 2018 and 2019).

However, the country still faces daunting challenges as malaria epidemiology exhibits enormous heterogeneity and complexity. The disease is mainly concentrated in tribal and remote areas of the country.

The Honorable Prime Minister of India was among the 18 East Asia Summit Leaders to pledge for malaria elimination in the country by 2030 in sync with the regional milestone, sustaining and progressing from the successful stride made through the decade. Against this background, the National Framework for Malaria Elimination (NFME) 2016 - 20309 was developed aligned with the Global Strategy for Malaria 2016 - 2030 (GTS) with the vision to eliminate malaria nationally and contribute to improve health, quality of life and alleviation of poverty. NFME in India was launched by the Union Health Minister in February 2016.

\section{Strategic Approaches for Malaria Control}

The NFME ${ }^{9}$ serves as a roadmap for advocating and planning malaria elimination throughout the country in a phased manner across 36 states and union territories. States/UTs have been subdivided into four categories (Table 1) with Annual Parasite Incidence (API) as the primary criteria and milestone and targets are set for 2020, 2024, 2027 and 2030. Malaria incidence in high transmission areas (Category must be lowered first before it is possible and rational to investigate each case. As per NFME in India, there are ten high transmission states (Arunachal Pradesh, Chhattisgarh,

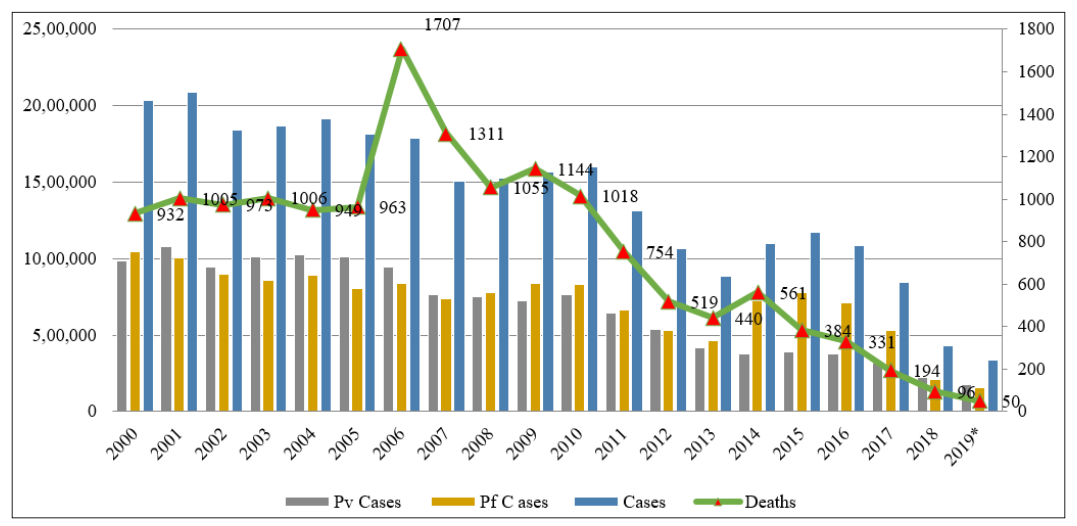

Figure 2. Trends of Malaria cases, deaths and Pf \& Pv cases from year 2000 to 2019 (NVBDCP) 
Jharkhand, Madhya Pradesh, Meghalaya, Mizoram, Odisha, Tripura, A\&N, D\&NH) under Category 3 having state API>1 and is targeted for ending malaria transmission by 2027.

National Strategy Plan for malaria elimination 2017-2022 ${ }^{10}$ has been developed by NVBDCP with the support of WHO country office, India in 2017 with focus on districtbased planning, implementation and monitoring of the programme for the five-year period to achieve the malaria elimination goals of NFME. The districts across all states and UTs have been categorized into four groups based on average reported API in the last three years (Table 2 ).

Table I.Classification of states/UTs based on API

\begin{tabular}{|c|c|c|}
\hline $\begin{array}{l}\text { S. } \\
\text { No. }\end{array}$ & Categories of states/UTs & Definition \\
\hline 1. & $\begin{array}{c}\text { Category 0: } \\
\text { Prevention of } \\
\text { establishment phase }\end{array}$ & $\begin{array}{c}\text { States/UTs with zero } \\
\text { indigenous cases of } \\
\text { malaria. }\end{array}$ \\
\hline 2. & $\begin{array}{c}\text { Category } 1 \\
\text { (Goa, Haryana, } \\
\text { Himachal Pradesh, } \\
\text { J\&K, Kerala, Manipur, } \\
\text { Punjab, Rajasthan, } \\
\text { Sikkim, Uttarakhand, } \\
\text { Chandigarh, Daman \& } \\
\text { Diu, Delhi, Lakshadweep, } \\
\text { Puducherry) }\end{array}$ & $\begin{array}{l}\text { States/UTs (15) } \\
\text { including their districts } \\
\text { reporting an API of } \\
\text { less than one case per } \\
1000 \text { population at } \\
\text { risk. }\end{array}$ \\
\hline 3. & $\begin{array}{c}\text { Category 2: Pre- } \\
\text { elimination phase } \\
\text { (AP, Assam, Bihar, } \\
\text { Karnataka, Maharashtra, } \\
\text { TN, Telangana, UP, WB, } \\
\text { Nagaland, Gujrat) }\end{array}$ & $\begin{array}{l}\text { States/UTs (11) with } \\
\text { an API of less than } \\
\text { one case per } 1000 \\
\text { population at risk, but } \\
\text { some of their districts } \\
\text { are reporting an API } \\
\text { of }>1 \text { case per } 1000 \\
\text { population at risk or } \\
\text { above. }\end{array}$ \\
\hline 4. & $\begin{array}{l}\text { Category 3: Intensified } \\
\text { Control Phase } \\
\text { (Arunachal Pradesh, } \\
\text { Chhattisgarh, Jharkhand, } \\
\text { MP, Meghalaya, Mizoram, } \\
\text { Odisha, Tripura, A\&N, } \\
\text { D\&NH) }\end{array}$ & $\begin{array}{c}\text { States/UTs }(10) \text { with } \\
\text { an API of one case per } \\
1000 \text { population at risk } \\
\text { or above. }\end{array}$ \\
\hline
\end{tabular}

The goal of this strategy is to eliminate malaria in Category 1 districts (API <1) by 2020 and Category 2 districts (API 1-2) by 2022 , while reducing transmission in Category 3 districts to stabilize API <1 by 2022 . The NSP has clearly articulated the objectives, strategies and time bound activities directed towards reducing malaria transmission.
Table 2.Categorization of districts in NSP

\begin{tabular}{|c|c|c|c|}
\hline $\begin{array}{l}\text { S. } \\
\text { No. }\end{array}$ & $\begin{array}{l}\text { Category of } \\
\text { Districts }\end{array}$ & Definition & $\begin{array}{c}\text { Number } \\
(\%)\end{array}$ \\
\hline 1. & $\begin{array}{l}\text { Category 0: } \\
\text { Prevention } \\
\text { of re- } \\
\text { establishment } \\
\text { phase }\end{array}$ & $\begin{array}{l}\text { Districts/Units } \\
\text { historically } \\
\text { considered to } \\
\text { be without local } \\
\text { transmission and } \\
\text { reporting no case } \\
\text { for last three } \\
\text { years. Vigilance } \\
\text { will be maintained } \\
\text { in these districts } \\
\text { to prevent } \\
\text { reintroduction of } \\
\text { malaria in view of } \\
\text { climate change. }\end{array}$ & 75 (11.0) \\
\hline 2. & $\begin{array}{l}\text { Category 1: } \\
\text { Elimination } \\
\text { Phase }\end{array}$ & $\begin{array}{l}\text { Districts/Units } \\
\text { having API less } \\
\text { than } 1 \text { per } 1000 \\
\text { population. }\end{array}$ & $448(66.1)$ \\
\hline 3. & $\begin{array}{l}\text { Category 2: } \\
\text { Pre-elimination } \\
\text { Phase }\end{array}$ & $\begin{array}{l}\text { Districts/Units } \\
\text { having API } 1 \text { and } \\
\text { above, but less } \\
\text { than } 2 \text { per } 1000 \\
\text { population. These } \\
\text { are positioned } \\
\text { for elimination } \\
\text { targeting in the } \\
\text { subsequent years. }\end{array}$ & $\begin{array}{c}46 \\
(6.8)\end{array}$ \\
\hline 4. & $\begin{array}{l}\text { Category 3: } \\
\text { Intensified } \\
\text { Control Phase }\end{array}$ & $\begin{array}{l}\text { Districts/Units } \\
\text { having API } 2 \text { and } \\
\text { above per } 1000 \\
\text { population. These } \\
\text { are positioned } \\
\text { for elimination } \\
\text { targeting in the } \\
\text { subsequent years. }\end{array}$ & 109 (16.1) \\
\hline
\end{tabular}

\section{High Malaria Burden States in India}

As per NFME, there are ten high burden states in Category 3 namely Arunachal Pradesh, Chhattisgarh, Jharkhand, Madhya Pradesh, Meghalaya, Mizoram, Odisha, Tripura, Andaman \& Nicobar Islands, Dadra \& Nagar Haweli. However, district wise classification has been done in NSP, in 2017, there were 109 districts under intensified Control Phase of Category 3. However, during the year 2019 (Provisional NVBDCP data), $90 \%$ of malaria cases were reported by nine states i.e. Uttar Pradesh (27.71\%), Chhattisgarh (18.10\%), Odisha (11.82\%), Jharkhand (10.92\%), West Bengal (7.75\%), Madhya Pradesh (4.11\%), Gujarat (4.01\%), Tripura (3.72\%), 
Maharashtra (2.65\%). Highest proportion of malaria deaths (34.00\%) has been reported from Chhattisgarh and this state also contributed highest proportion of (31.75\%) of Pf cases in the country.

\section{Progress - Adaptation of $\mathrm{HBHI}$ in India}

In 2019, HBHI approaches are being adopted by National Vector Borne Diseases (NVBDCP) with the support of WHO in four high burden states namely Madhya Pradesh Jharkhand, Chhattisgarh, and West Bengal. The progress for adaptation of $\mathrm{HBHI}$ is given below:

\section{Meeting on $\mathbf{H B H I}$}

The WHO Country Office and NVBDCP organized a meeting of high malaria burden states in India with participation of WHO HQ, Regional office and the RBM Partnership to discuss the adaptation of HBHI approach on 13 \& 14 May 2019 at Bhopal, Madhya Pradesh. Eight States were invited for the review meeting i.e. Andhra Pradesh, Telangana, Maharashtra, Chhattisgarh, Jharkhand, Odisha, West Bengal and Madhya Pradesh. Odisha could not participate due to its on-going response to Cyclone "Fani" that hit 15 districts of the State. During the meeting, an in-depth review of the malaria situation in the participating states, was presented, identifying challenges and gaps and prioritizing issues for support under the $\mathrm{HBHI}$ approach. It was decided in the meeting, initially $\mathrm{HBHI}$ would be adopted in four states in the country.

Training on HBHI Approach: Two training workshops for district level officers and consultants were organized in Chhattisgarh from 13-16 November 2019 and in Madhya Pradesh from 2-5 December 2019 by WHO in collaboration with NVBDCP. The States were oriented on the $\mathrm{HBHI}$ approach, including "Zero Malaria Starts with Me". The main objectives of the training were:

- To update the knowledge and skills of the participants on malaria control and elimination, including the $\mathrm{HBHI}$ approach.

- To analyze state- and district-specific determinants of malaria and its control.

- To identify best practices, lessons learned and the key challenges to be addressed in controlling malaria.

- To develop context-specific approaches to accelerate malaria burden reduction in each district in the states included in the $\mathrm{HBHI}$ approach.

- To draft malaria control program district operational plans for the remaining part of FY 2019-2020 and for FY 2020-2021.

First training workshop was conducted from 13-16 November 2019 at Raipur, Chhattisgarh. State Program Officer and vector Borne Diseases State/ District Consultants and District Malaria Officers from all districts were participated (Figure 3). There were total 52 participants from the state.
The training workshop was also attended by the Director, NHM and Director Health Services, Chhattisgarh.

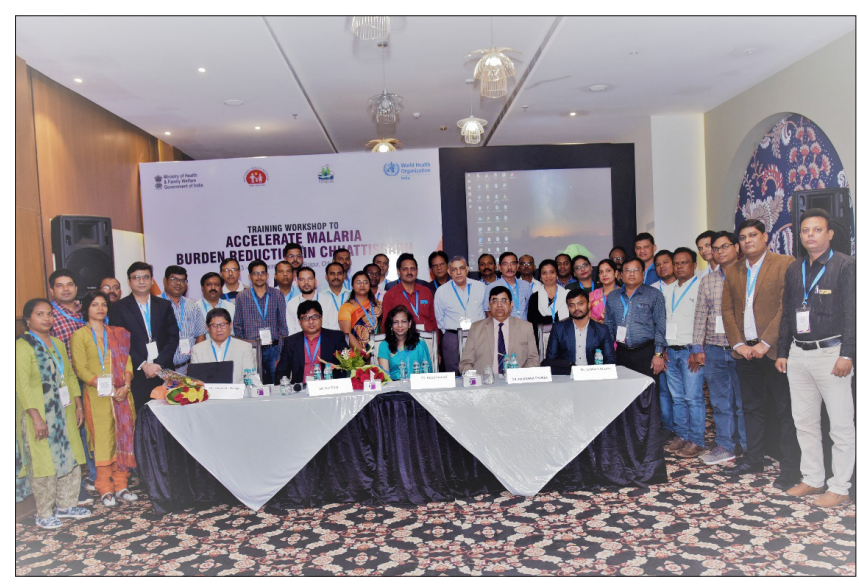

Figure 3.Training on HBHI from I3-16 November 2019 at Raipur, Chhattisgarh

Last day, the representative from each district presented the malaria situation and draft operational plans of the in the respective district that was reviewed by the faculties. Experts from WHO Country office as well as from GMP, WHO HQ and other national experts were the resource person for the training workshop.

The four days WHO supported training workshop on $\mathrm{HBHI}$ approaches was also organized from 2-5 December 2019 at Bhopal, Madya Pradesh. Total 60 participants from the state and districts were participated. Senior Health Officers of the state also participated.

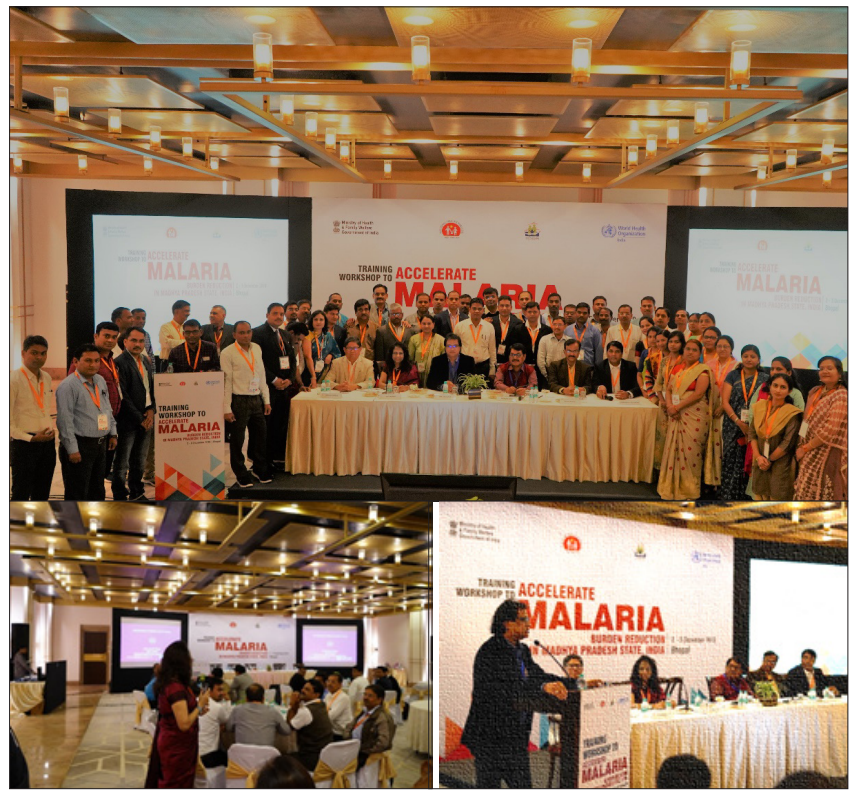

Figure 4. Training workshop for District Malaria Officers on HBHI approaches at Bhopal, Madhya Pradesh from 2-5 December 2019 
Participants from each district drafted operational plans to define specific responses to key challenges, prioritize them (as high, Medium or Low), indicate the timelines, define the expected outputs and link as whenever feasible to one or more of the four response elements in the $\mathrm{HBHI}$ approach (Figure -3 \& 4). Experts from WHO and NVBDCP supported the districts to finalize operational plans aligned with $\mathrm{HBHI}$ approaches.

\section{Situation Analysis}

It has been decided to adopt the $\mathrm{HBH}$ approach initially in four high burden states Chhattisgarh, Jharkhand, West Bengal and Madhya Pradesh. Each state will be supported to develop its state specific strategic plan and operational plan. The strategic plan will be based on an in-depth situation analysis in each of the four states using the HBHI approach.

Four consultants were deputed by WHO country office during the year 2019, one assigned to each state to conduct are situation analysis by applying WHO tools and to identify the gaps/challenges. These will be helpful for developing state strategic plans aligned with four pillars of $\mathrm{HBHI}$, which will also include costing for the new activities to be borne from GOI/ state funds/WHO and for appropriate reflection of funds accordingly in state Program Implementation Plan (PIP). The institutionalization of the approach will help accelerate and sustain the progress in reducing the malaria burden and achieve malaria elimination in India. This will require, among others, strengthening the technical and managerial capacities in malaria program at all levels of the health system. Situation analysis has been carried out in all four states. The situation analysis of malaria in one of the states i.e. Madhya Pradesh is provided in this paper.

\section{Madhya Pradesh}

Madhya Pradesh is India's second largest state with an area of $3,08,252 \mathrm{sq}$. km. The present Projected Population of the state is 80.15 million, having 51 districts. The state, has 14.7 percent of India's total tribal population There are Multi-Purpose Workers (MPW) male, ANM along with 64,105 ASHA workers at periphery, who are engaged in recognition of fever cases with symptoms of malaria and their diagnosis either with microscopy at $\mathrm{DH} / \mathrm{CH} / \mathrm{CHC} / \mathrm{PHC}$ level or with RDT at village level.

\section{Malaria Situation Analysis}

Madhya Pradesh contributes about $6.5 \%$ population and $6.3 \%$ Malaria load of the country. Malaria Elimination has been targeted in the state since year 2016. Malaria cases decreased by $31.79 \%$ during the year 2017 as compared to the year 2016. Malaria cases have declined by $79 \%$ from 2015 to 2018. However, in 2018 the cases declined by $55 \%$ as compared to 2017 . During 2017, 5 deaths were reported from the state while only one death was reported in 2018 and one in 2019. Similarly, number of Plasmodium falciparum cases has also declined by $83.54 \%$ by the year 2018 as compared to the year 2015. Malaria cases have been declined more in 2019 (13757) as compared to corresponding period of 2018 (22279). P. falciparum cases recorded during the year 2018 \& 2019 were 6332 and 3515 respectively. Overall, there is drastic decline in malaria morbidity and mortality from 2015 to 2019.

Malaria Vector: An culicifacies is main vector in plains and low-lying areas. The main vector in hilly areas is An. fluviatilis. Thus, there are two clear cut zones under the influence of these two vectors and both seem to play role in malaria transmission in the transition belt. The peak transmission would appear to be September to November.

There are five entomological zones (Bhopal, Indore, Jabalpur, Gwalior \& state Headquarter) in the state. Entomological surveillance needs to be strengthened in the state.

\section{Stratification}

During year 2015, 5 districts namely Jhabua, Sheopur, Dindori, Mandla and Alirajpur were highly endemic, showing API 10.48, 8.02, 6.36, 4.03 and 4.0 respectively. All these districts have forest areas, with predominantly tribal populations. Another five districts namely Balaghat, Shivpuri, Anuppur, Sidhi \& Betul where API was in between 2 to 3. During year 2016 only three districts namely Jhabua, Sheopur \& Dindori were highly endemic having API 6.46, $5.05 \& 4.44$, respectively. Only one district Shivpuri is having API 2.04, other 13 districts were less than 2 API, while 34 districts were below 1 API. During year 2017 only two districts namely Sheopur \& Anuppur were highly endemic having API 6.34, \& 4.53 respectively, Annupur district was having API less than two during year 2016 but have shown increase to 4.53 API during year 2017. Only one district Jhabua is having API 2.01, other 4 districts were showing API less than 2, while 44 districts were below 1 API. It clearly indicates that the incidence of malaria is going down every year. Proportionate malaria cases in high burden districts during the year 2016, 2017 and 2018 is given at Figure 4.

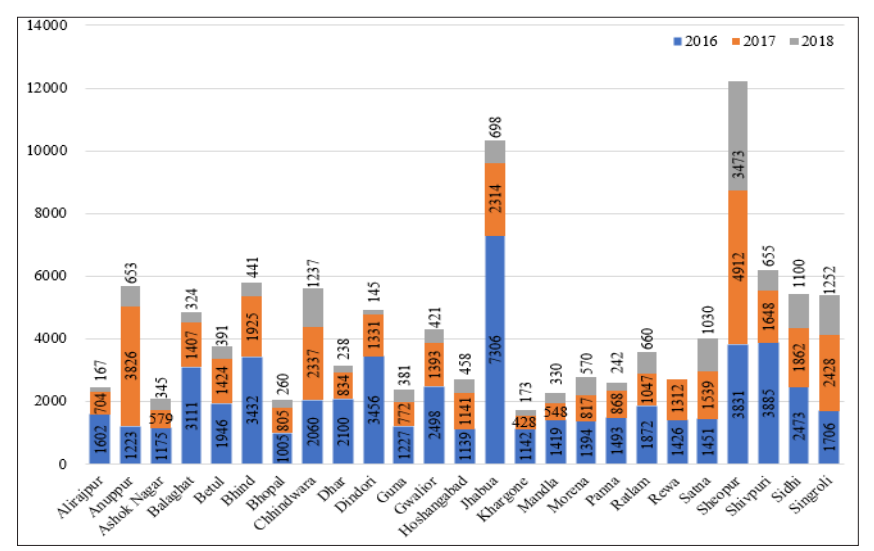

Figure 5.Malaria cases in high burden districts in Madhya Pradesh in 2016, 2017 and 2018 


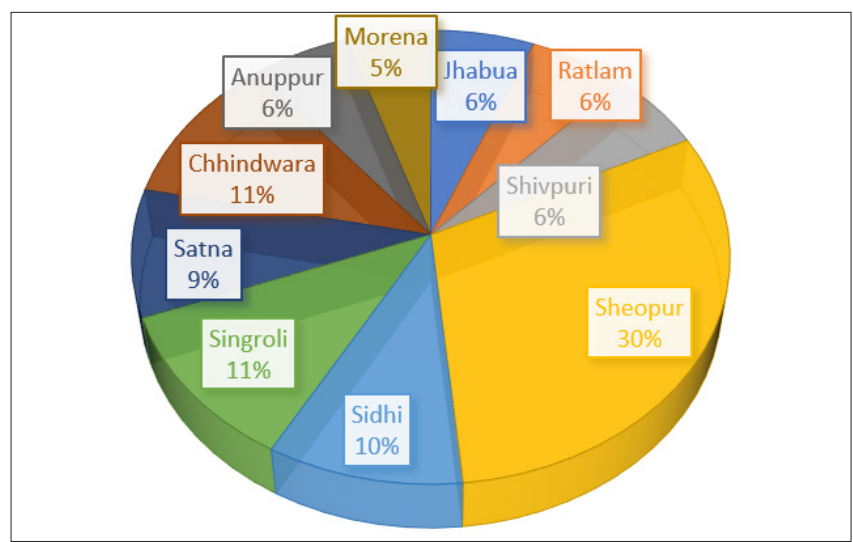

Figure 6.Percent contribution of malaria cases by different districts in Madhya Pradesh during 2018

Figure 5, is showing percent contribution of malaria cases by different districts in Madhya Pradesh during 2018. Total of 51 districts, 9 districts namely Sheopur, Ratlam, Shivpuri, Sidhi, Singroli, Satna, Jhauba, Anupur and Chhindwara reported $50.85 \%$ cases of the state. Remaining cases reported from 42 districts. Sheopur district alone contributed $30 \%$ malaria cases of the state, having more than 1 API (4.42), rest other 50 districts are below 1 API (Figure 6).

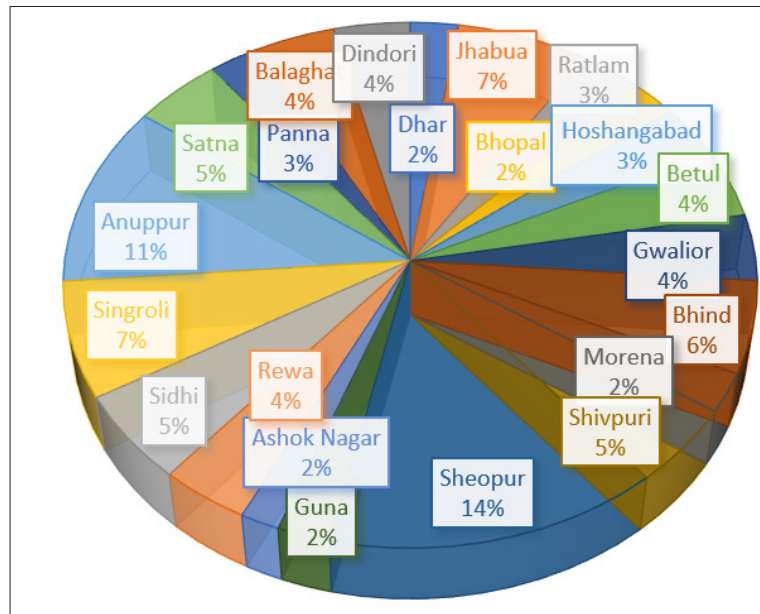

Figure 7.Percent contribution of malaria cases in high burden districts in Madhya Pradesh for 2017 and 2018

Figure 7 , shows that in $2017,14 \%$ of malaria contributed by Shivpuri while in $201830 \%$ contributed by this district. Malaria cases was increased in 2018 as compared to 2017. API wise stratification of districts (Table 1) has been done, accordingly there are 26 districts $>1$ API during the year 2015, 17 districts during year 2016, 7 districts during year 2017 \& 1 district respectively recorded in 2018.

Based on 2015 data, the state of Madhya Pradesh was kept in Category 3 (more than $1 \mathrm{API}$ ) in NFME, but after that it is found that malaria burden is continuously declining in the state. As shown in table, districts are gradually shifting to
Category 1 and there is only one district with high burden (above API 1) in Category 3 during the year 2018.

Table I.Stratification of districts from 2015 to 2018

\begin{tabular}{|c|c|c|c|c|c|c|c|}
\hline \multirow[b]{2}{*}{ Year } & \multirow{2}{*}{$\begin{array}{l}\text { API } \\
\text { of } \\
\text { State }\end{array}$} & \multicolumn{4}{|c|}{$\begin{array}{l}\text { API grouping showing } \\
\text { number of districts }\end{array}$} & \multirow{2}{*}{$\begin{array}{l}\text { Total } \\
\text { dist- } \\
\text { ricts } \\
\text { >1 API }\end{array}$} & \multirow{2}{*}{$\begin{array}{c}\text { Total } \\
\text { dist- } \\
\text { ricts } \\
<1 \\
\text { API }\end{array}$} \\
\hline & & $\begin{array}{l}\text { API } \\
>10\end{array}$ & $\begin{array}{c}\text { API } \\
5-9.9\end{array}$ & $\begin{array}{c}\text { API } \\
2- \\
4.9\end{array}$ & $\begin{array}{c}\text { API } \\
1- \\
1.9\end{array}$ & & \\
\hline 2015 & 1.2 & 1 & 2 & 7 & 16 & 26 & 24 \\
\hline 2016 & 0.85 & 0 & 2 & 2 & 13 & 17 & 34 \\
\hline 2017 & 0.5 & 0 & 1 & 2 & 4 & 7 & 44 \\
\hline 2018 & 0.3 & 0 & 0 & 1 & 0 & 1 & 50 \\
\hline
\end{tabular}

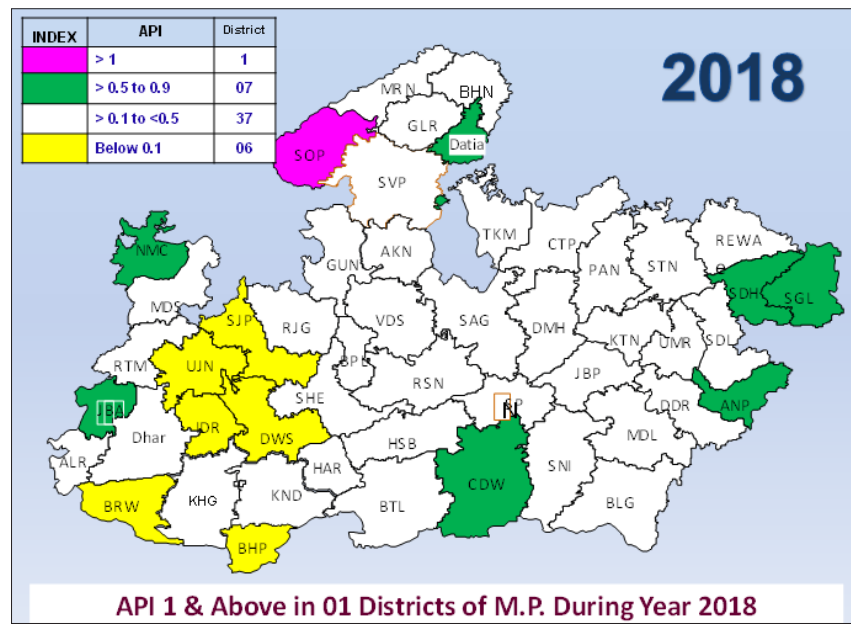

Figure 8.Map showing endemicity of districts based on API in Madhya Pradesh

There are 313 Blocks in the state, out of which 20 blocks in 15 districts are $>1$ API during year 2018, while 120 blocks were $>1$ API during year 2015 (Table 2). On further stratification during year 2018, 1 block is above 10 API, 2 blocks are between 5 to $9.9 \mathrm{API}, 5$ blocks are between 2 to $4.9 \mathrm{API}, 12$ blocks are between 1 to $1.9 \mathrm{API}$. Thus, 20 blocks are above 1 API in 2018 where focused attention is required to implement the appropriate preventive measures on to reduce the disease burden further. The remaining 293 blocks (93.6\%) are below 1 API during year 2018 where case-based surveillance and foci investigation to be carried out in a systematic way.

\section{Micro Stratification at Sub-Health Center (SHC) Level}

There are 11,264 SHCs in the state, out of which 652 SHCs in 50 districts are $>1 \mathrm{API}$ during the year 2018, while 1,951 SHCs were $>1$ API during year 2016 (Table 3). On further stratification during year 2018, 5 SHCs are between 25 to 49.9 API, $13 \mathrm{SHCs}$ are between 10 to $24.9 \mathrm{API}, 46 \mathrm{SHCs}$ are between 5 to $9.9 \mathrm{API}, 204$ SHCs are between 2 to $4.9 \mathrm{API}$ \& 384 SHCs are between 1 to $1.9 \mathrm{API}$. 
Table 2.Stratification of blocks (CHC) level from 2015 to 2018

\begin{tabular}{|c|c|c|c|c|c|c|c|c|}
\hline \multirow{2}{*}{ API } & \multicolumn{2}{|c|}{2015} & \multicolumn{2}{c|}{2016} & \multicolumn{2}{c|}{2017} & \multicolumn{2}{c|}{2018} \\
\cline { 2 - 10 } & $\begin{array}{c}\text { No. of } \\
\text { blocks }\end{array}$ & \% block & $\begin{array}{c}\text { No. of } \\
\text { blocks }\end{array}$ & \% block & $\begin{array}{c}\text { No. of } \\
\text { blocks }\end{array}$ & \% block & $\begin{array}{c}\text { No. of } \\
\text { blocks }\end{array}$ & \begin{tabular}{c} 
\% block \\
\hline$>10$
\end{tabular} \\
\hline 12 & 3.51 & 3 & 3.51 & 2 & 0.6 & 1 & 0.31 \\
\hline $5-9.9$ & 11 & 3.51 & 9 & 3.51 & 5 & 1.5 & 2 & 0.63 \\
\hline $2-4.9$ & 40 & 12.46 & 24 & 12.46 & 20 & 6.3 & 5 & 1.59 \\
\hline $1-1.9$ & 57 & 18.21 & 37 & 18.21 & 35 & 11.1 & 12 & 3.83 \\
\hline$<1$ & 193 & 55.91 & 240 & 55.91 & 251 & 80.5 & 293 & 93.6 \\
\hline Total blocks & 313 & & 313 & & 313 & & 313 & \\
\hline
\end{tabular}

Table 3.Grouping of SHC based on API during year 2018

\begin{tabular}{|c|c|c|c|c|c|c|c|c|}
\hline \multirow{2}{*}{ Year } & \multicolumn{7}{|c|}{ API Grouping of SHCs } & \multirow{2}{*}{$\begin{array}{c}\text { Total No. of } \\
\text { SHCs > 1 API }\end{array}$} \\
\cline { 2 - 10 } & API $>\mathbf{1 0 0}$ & API 50-99.9 & API 25-49.9 & API 10-24.9 & API 5-9.9 & API 2-4.9 & API 1-1.9 & SHCs \\
\hline 2016 & 3 & 2 & 16 & 103 & 229 & 685 & 913 & 1,951 \\
\hline 2018 & 0 & 0 & 5 & 13 & 46 & 204 & 384 & 652 \\
\hline
\end{tabular}

\section{District wise SHCs > I API}

\begin{tabular}{|c|c|c|c|c|c|c|c|c|}
\hline $\begin{array}{l}\text { S. } \\
\text { No. }\end{array}$ & Name of district & $\begin{array}{c}\text { No. of } \\
\text { SHC >1API }\end{array}$ & $\begin{array}{l}\text { S. } \\
\text { No. }\end{array}$ & $\begin{array}{l}\text { Name of } \\
\text { District }\end{array}$ & $\begin{array}{c}\text { No. of SHC } \\
>1 \mathrm{API}\end{array}$ & $\begin{array}{l}\text { S. } \\
\text { No. }\end{array}$ & $\begin{array}{l}\text { Name of } \\
\text { district }\end{array}$ & $\begin{array}{l}\text { No. of SHC } \\
>1 \mathrm{API}\end{array}$ \\
\hline 1. & Sheopur & 68 & 15 & Katni & 14 & 28 & Guna & 6 \\
\hline 2. & Chhindwada & 60 & 16 & Satna & 14 & 29 & Neemuch & 6 \\
\hline 3. & Singrouli & 53 & 17 & Shivpuri & 14 & 30 & Alirajpur & 5 \\
\hline 4. & Jhabua & 52 & 18 & Narsingpur & 13 & 31 & Rajghar & 5 \\
\hline 5. & Sidhi & 51 & 19 & Dindori & 11 & 32 & Damoh & 4 \\
\hline 6. & Anuppur & 40 & 20 & Ashoknagar & 10 & 33 & Sagar & 3 \\
\hline 7. & Ratlam & 26 & 21 & Bhind & 10 & 34 & Vidisha & 3 \\
\hline 8. & Betul & 24 & 22 & Datia & 9 & 35 & Gwalior & 2 \\
\hline 9. & Seoni & 20 & 23 & Tikamgarh & 9 & 36 & Harda & 2 \\
\hline 10. & Balaghat & 19 & 24 & Umaria & 9 & 37 & Mandsour & 2 \\
\hline 11. & Mandla & 17 & 25 & Shahdol & 8 & 38 & Raisen & 2 \\
\hline 12. & Morena & 16 & 26 & Panna & 7 & 39 & Khandwa & 1 \\
\hline 13. & Rewa & 16 & 27 & Dhar & 6 & 40 & Sehore & 1 \\
\hline 14. & Hoshangabad & 14 & & & & & & \\
\hline & $\begin{array}{c}\text { Total districts - 40, No. } \\
\text { of SHCs > } 1 \text { API - } 652\end{array}$ & & & & & & & \\
\hline
\end{tabular}

There are 11,264 SHCs in the state, out of which 652 SHCs in 50 districts are $>1$ API during year 2018, while 1,951 SHCs were $>1$ API during year 2016 .

On further stratification during year 2018, 5 SHCs are between 25 to $49.9 \mathrm{API}, 13 \mathrm{SHCs}$ are between 10 to $24.9 \mathrm{API}$, 46 SHCs are between 5 to 9.9 API, 204 SHCs are between
2 to $4.9 \mathrm{API} \& 384 \mathrm{SHCs}$ are between 1 to $1.9 \mathrm{API}$. Thus 652 SHCs are above 1 API where preventive measures are planned on priority. Rest 10,623 SHCs are below 1 API during year 2018.

\section{Urban Malaria Profile}

An Urban malaria Scheme is functioning in six towns Viz 
Bhopal, Indore, Ratlam, Ujjain, Mandsore and Shivpuri. Bhopal and Ratlam town reported maximum malaria cases. Epidemiological data indicates that Annual Blood Examination Rate (ABER) is ranging from 12.59 to 11.39 in years 2015 to 2018, API has also declined from 0.56 during year 2015 to 0.08 during year 2018. It is observed that the surveillance operation includes only passive surveillance and surveillance data from nursing homes, laboratories and private clinics in the town. Hence, surveillance through ASHA/ USHA in urban area need to be strengthened.

\section{Challenges and Gap Analysis}

\section{Mobile and Migrant Populations}

Migration has been a consistent phenomenon in the state of Madhya Pradesh from malaria endemic states such as Chhattisgarh \& Gujrat and vice-versa in search of livelihood, making the indigenous population vulnerable to malaria infection. In Dindori district, (Mehandwani Block) - every year people migrate to Khammam District of Telangana state, (Block Palvanse) for cutting of bamboo tree during month of October and November and return back with $P$. falciparum infection. During the year 2016, 2017, 2018 and 2019 , the numbers of migrated/imported $P$. falciparum cases were 26, 38, 19 and 12 respectively. There is need for mapping of such places with aggregation of high-risk migrant populations to ensure that they are screened for malaria on their arrival and covered routinely under surveillance.

Thus, transitional transmission foci should be monitored by both the states and interstate border meetings should be revived to monitor and coordinate.

\section{Epidemiological Gaps}

Since the proportion of $P$. vivax is more in Madhya Pradesh (2019 - 74.5\%; 2018 - 74.4\% 2017 - 66\%), there is challenges to follow complete radical treatment of $P$. vivax malaria and monitoring of relapses. Fourteen days radical treatment needs to be followed.

\section{Human Resource}

It is an enormous challenge to ensure that key interventions are delivered timely as M'PW male workers are not sufficient in number for optimal performance. There are 11,264 SHCs in the state and only 4260 sanctioned posts of MPW Male with state. Even out of these sanctioned posts, 253 are lying vacant. This results in an overburdening of health care staff, which coupled with low financial remuneration, leads to low moral and poor performance. The post of DMO/DVBDO in highest burden district of Sheopur (highest malaria burden district) is lying vacant since April, 2019. It is difficult to manage by temporary arrangement as consultant in the district where maximum number of cases are reported. The post of state entomologist and three posts of regular zonal entomologists, 11 DMOs, 31 AMOs and 133 malaria inspectors are vacant.

All vacant post should be filled up by the state at the earliest

\section{Vector Control}

Vector control interventions were highly targeted in malaria high-risk SHC's (predominantly tribal) in most districts and ignoring the other high malaria burden villages which do not qualify under criteria i.e. SHC more than 1 API. The state entomological teams carried out susceptibility studies to conventional insecticides in different districts. An. culicifacies showed resistance to DDT and malathion in all the districts. So alternative IRS compounds (Synthetic Pyrethroids) should be used judiciously. It was observed that there is low acceptance of Indoor Residual Spray.

Data for Insecticide resistance and Changing behaviour of vectors to be studied for effective planning of vector control. Foci based vector control interventions need to be strengthened in low endemic areas.

\section{Surveillance}

The state has yet to declare malaria as notifiable disease. Presently, total of 51 districts, 50 districts have a smaller number of malaria cases (below $1 \mathrm{API}$ ), there are challenges to accelerate malaria elimination activities by strengthening case-based surveillance and foci investigation.

There is need to strengthen surveillance system to ensure $100 \%$ parasitological diagnosis of all suspected malaria cases and complete treatment of all confirmed cases within 24 hours. Mapping of private sector hospitals and reporting need to be augmented.

\section{Governance}

The state Task Force Committee on malaria Elimination is not constituted in the state. However, the districts have already coordination committee on malaria under District Magistrate. It should be redesigned as District Coordination Committee on malaria Elimination.

\section{Best Practices}

- $\quad$ ASHA is actively involved for diagnosis and treatment at the community level. The Bivalent Rapid Diagnostic Kits (RDT), Chloroquine tablets, Artesunate Combination Therapy (ACT) and Primaquine (for radical treatment) are available up to the ASHA level. The state has been arranged training for ASHA workers to use of RDT.

- Out of total 6332 Pf cases in 51 districts, 2957 Pf cases (93.46\%) were detected by RDT during year 2018 \& treated on the same day. The detection of Pf cases has improved with the use of RDT.

- Information Education and communication activities for malaria and other VBDs have been seen in all 51 districts of state to create awareness in the community. 
Before inception of IRS activities in villages community are well informed for better coverage and benefits of spray. Fever camps are also arranged in highly endemic villages.

- In 2017-18; a total of 1.37 million Long Lasting Insecticidal Nets (LLINs) were supplied by NVBDCP for high malaria endemic districts. Another 94.6 Lakh have been provided during 2018-2019 under GFATM support for saturation of all high endemic population in subcenters with API 1 and above in the entire state.

\section{Way Forward}

- Based on stratification, micro strategic plans will be developed to fulfill those gaps and to accelerate malaria elimination activities in the districts of Madhya Pradesh. This stratification ae useful for target intervention in low endemic areas and to chive universal coverage of intervention in high burden areas. Similarly, situation analysis of all other three states (Chhattisgarh, West Bengal and Jharkhand) have been also carried out. During HBHI training, participants (DMOs \& DVBDO) have been trained for preparation for an effective district operational plans by analyzing of their own data to stratified areas up to village levels. These Operational plans need to be implemented timely and effectively in all districts to achieve target for malaria elimination and sustain reduction of malaria morbidity and mortality. Interventions and response would be different for low endemic areas as well as in high burden areas Mid-term review should be also carried out.

- In all high burden states, there are low burden districts/ blocks/subcenters having API less than 1 , so casebased surveillance and foci investigation need to be strengthened in low endemic areas.

- Interstate border meetings with bordering states may be organized at a regular basis.

- Entomological capacity needs to be strengthened in the state to scale up entomological surveillance and to generate data on vector susceptibility for updating the resistance status in the state.

\section{Acknowledgment}

The authors are thankful to state health authorities of Madhya Pradesh for sharing information and data, which have been mentioned in this paper. We also acknowledge with thanks, the work done by Dr R.S. Sharma, Former Head \& Additional Director, CME\&VM, NCDC, in Madhya Pradesh while working as SSA, WHO.

We also thank Dr. Leonard Ortega, Team leader, GMP, WHO and Dr. Vokaty Alexandra, Team Leader (CD), WHO Country Office, India for overall guidance.

\section{Abbreviations}

- ABER: Annual Blood Examination Rate
- ANM: Auxiliary Nurse Midwifery

- API: Annual Parasite Incidence

- ASHA: Accredited Social Health Activist

- CHC: Community Health Center

- GTS: Global Technical strategy

- IRS: Indoor Residual Spraying

- $\quad$ LLINs: Long Lasting Insecticide Treated Nets

- NVBDCP: National Vector Borne Disease Control Program

- NFME: National framework for Malaria Elimination

- NSP: National Strategy Plan

- DMO: District malaria Officer

- DVBDO: District Vector Borne Disease Officer

- MPW: Multi-Purpose Worker

- Pv: Plasmodium Vivax

- Pf: Plasmodium falciparum

- PHC: Primary Health Center

- PIPs: Program Implementation Plan

- $\quad$ RDT: Rapid Diagnosis Test kit

\section{Conflicts of Interest: None}

\section{References}

1. World Health Organization 2015. The Global Strategy for Malaria 2016-2030 (GTS). Available from: https://www. who.int/malaria/publications/atoz/9789241564991/ en/.

2. World Health Organization. 2018. World Malaria Report 2018. WHO, Geneva..https://www.who.int/malaria/ publications/world-malaria-report-2018/en/

3. World Health Organization. 2019. World Malaria Report 2019. WHO, Geneva. https://www.who.int/ publications-detail/world-malaria-report-2019

4. World Health Organization 2019. High Burden High Impact - A targeted malaria response. WHO and RBM partnership to end malaria. Available from: https:// apps.who.int/iris/bitstream/handle/10665/275868/ WHO-CDS-GMP-2018.25-eng.pdf?ua=1.

5. The RBM Partnership to End Malaria. Zero Malaria Starts with Me Toolkit. Available from: https:// endmalaria.org/sites/default/files/Zero\%20Malaria\%20 Toolkit\%20Final.pdf

6. Sub-Saharan leaders deliver progress on "HBHI" response.2019 Available from: https://reliefweb. int/report/world/high-burden-high-impact-targetedmalaria-response.

7. WHO and The RBM Partnership to End Malaria 2020. "Zero malaria starts with me" campaign. Available from : https://www.who.int/news-room/campaigns/ world-malaria-day/world-malaria-day-2020

8. WHO. "HBHI" response in Africa. 2019. Available from: https://www.who.int/news-room/feature-stories/ detail/sub-saharan-leaders-deliver-progress-on-highburden-to-high-impact-response. 
9. National Framework for Malaria Elimination 2016 2030. Directorate of National Vector Borne diseases, Directorate General of Health Services, Ministry of Health \& Family Welfare Government of India. NVBDCP, 2016.

10. National Strategic Plan for malaria elimination 20172022, Directorate of National Vector Borne diseases, Directorate General of Health Services, Ministry of Health \& Family Welfare Government of India 2017.

11. Das A, Anvikar AKR, Cator $\sqcup$, et al. Malaria in India: the center for the study of complex malaria in India. Acta Trop. 2012; 121(3): 267-73. 